\title{
Marta Suárez-Varela*
}

\author{
Andrea Vanessa Robalino-Molina**
}

\section{PATRONES MIGRATORIOS ENTRE ÁFRICA Y EUROPA: EL ROL DE LA INSEGURIDAD ALIMENTARIA}

En este artículo, nuestro objetivo es medir la influencia de la inseguridad alimentaria en los flujos migratorios entre África y Europa. Utilizando una muestra de datos para los países de estos dos continentes para el periodo 2000-2018, y a través de modelos de tipo probit, concluimos que, incluso una vez controlados otros factores como los conflictos, desastres naturales o las diferencias de ingresos, la inseguridad alimentaria podría constituir un factor explicativo adicional de los flujos migratorios entre África y Europa.

\section{Migration patterns between Africa and Europe: the role played by food insecurity}

Our aim in this paper is to measure the influence of food insecurity in the migration flows between Africa and Europe. To do so, we use a sample including data from countries of the two continents from 2000 to 2018, and employing probit models, we conclude that even after controlling for other factors such as conflicts, natural disasters or income differences, food insecurite arises as an additional explanatory variable of the migration flows between Africa and Europe.

Palabras clave: migración internacional, refugiados, solicitantes de asilo, seguridad alimentaria, África, Europa.

Keywords: international migration, refugees, asylum seekers, food safety, Africa, Europe.

JEL: F220, J11, Q18.

\footnotetext{
* Departamento de Estructura Económica y Economía del Desarrollo. Universidad Autónoma de Madrid, España.

** Universidad Autónoma de Madrid, España.

Agradecimientos: Este artículo se elaboró en el marco del proyecto de referencia 599794-EPP-1-2018-1-ES-EPPJMO-Network con el título «The European Union, Mediterranean and Africa integration in the Global Age» AMENET. Los autores agradecen el apoyo recibido por dicho proyecto. Versión de marzo de 2020.

DOI: https://doi.org/10.32796/ice.2020.914.7026
} 


\section{Introducción}

La importancia de las migraciones en el ámbito internacional se encuentra en continuo ascenso. De hecho, estadísticas recientes sobre migración proporcionadas por la División de Población de las Naciones Unidas señalan que solo en 2019 se contabilizaron 271 millones de migrantes internacionales, en tanto que en 1990 esta cifra únicamente ascendía a 153 millones, lo que implicaría un incremento del $77,5 \%$ en el período comprendido desde 1990 a 2019 (OIM, 2018). De acuerdo con la Comisión Española de Ayuda al Refugiado (CEAR), «las migraciones se han convertido en un proceso demográfico natural que no es ajeno a ninguna región del planeta, a ningún momento histórico ni al propio ser humano desde sus orígenes» (Comisión Española de Ayuda al Refugiado, 2016).

En la Unión Europea, la migración es actualmente una de las principales fuerzas modeladoras de las dinámicas poblacionales (Comisión Europea, 2018). En efecto, esta región es uno de los principales destinos de las migraciones de Latinoamérica, el Caribe y, desde el año 2015, de países como Oriente Medio, África, los Balcanes Occidentales y Asia del Sur (Comisión Europea, 2016). Los datos de Eurostat señalan que, en el período 2012-2017, el número de migrantes en la UE se incrementó hasta en un $30 \%$, pasando de 3,5 millones de personas a 4,6 millones. Llama particularmente la atención el acusado incremento experimentado entre los años 2013 y 2015 , en los que la migración se incrementó en un $34 \%$ desde los 3,6 millones de personas a 4,8 millones, registrando de este modo un aumento de 1,2 millones en tan solo 3 años (Eurostat, 2019a).

El análisis de la procedencia de los migrantes revela que en promedio más del $40 \%$ del total son de países no miembros de la UE. Mientras que en 2013 solo representaban el 39,4\% del total, para 2017 la cifra se situaba en el 45,1\% (Eurostat, 2019b). El incremento del flujo migratorio a la UE en 2014 y 2015 se da como resultado de una multiplicidad de factores. La proximidad geográfica con regiones que sufren altas presiones migratorias es uno de los principales factores que han motivado y facilitado el desplazamiento de la población, ya que reduce los costes de transporte y de adquirir información sobre los destinos (FAO, IFAD, IOM y WFP, 2018). En particular, estos desplazamientos se han producido desde países vecinos a la Unión Europea pertenecientes a Oriente Medio, África, los Balcanes Occidentales y Asia del Sur, entre los que se encuentran algunos como Siria, Afganistán, Eritrea, Sudán o Nigeria (Eurostat, 2019b).

Este flujo migratorio ha sido considerado como una diáspora (Ministerio de Asuntos Exteriores, 2018), en tanto que se trata de una crisis migratoria ${ }^{1}$ ocurrida de manera inesperada y que ha involucrado la movilización de miles de personas en situación de vulnerabilidad. Dado que no ocurría desde la Segunda Guerra Mundial un flujo de este tipo (ACNUR, 2015), la Unión Europea ha visto incluso superados los mecanismos contemplados para su manejo, control y gestión (Comisión Europea, 2016). La consolidación de este patrón migratorio, basado en la entrada masiva de migrantes y solicitantes de asilo que han ingresado en la Unión Europea en condición de vulnerabilidad y precariedad, ha derivado en última instancia en una crisis humanitaria.

En relación al contexto africano, África es el tercer continente más extenso del mundo con particularidades históricas, geográficas, culturales, económicas y geopolíticas que han delineado su consolidación como un continente con una multiplicidad de ecosistemas, lenguas, pueblos y etnodiversidad. La pluralidad geográfica de África ha determinado la especialización y el desarrollo económico de cada una de las regiones que la conforman, entendiéndose por tanto el continente

1 OIM (2019) define la crisis migratoria como flujos migratorios complejos y, a menudo, a gran escala, con patrones de movilidad causados por una crisis que generalmente implican vulnerabilidades significativas para las personas y las comunidades afectadas y generan desafíos agudos y de gestión de la migración. 
africano como el conjunto de sus diversos ecosistemas (OCDE-FAO, 2016). El desierto del Sahara es un límite de demarcación claro dentro de las disparidades geográficas que África presenta. Mientras que la parte norte, por su cercanía con el continente euroasiático, ha enfrentado un desarrollo económico y social mayor con respecto al resto de regiones de África, África subsahariana ha quedado rezagada en su desarrollo económico y social.

Al desarrollo económico disímil de las regiones de África hay que añadir la existencia de conflictos armados recurrentes o guerras civiles en determinadas regiones. Entre ellos, destacan los de Somalia desde 1991; el conflicto limítrofe entre Chad y Sudán en 2005 que ha provocado el desplazamiento forzado de la población más vulnerable; la aparición del grupo insurgente Boko Haram; la guerra civil de Sudán del Sur desde 2013; la segunda guerra civil en Libia y las continuas insurrecciones e inestabilidad política en países como Egipto, la República Centroafricana, el Congo, Etiopía, Argelia, Túnez, Burundi y Mali (FAO, 2017). Asimismo, en un escenario en los que desastres naturales y el cambio climático son factores multiplicadores de problemas ambientales, la falta de disponibilidad de recursos ocasiona incertidumbre por el acceso limitado a los medios de vida y al suministro de alimentos (FAO, 2017), exacerbando además las condiciones de extrema pobreza en regiones donde la gestión y mitigación del riesgo de desastres naturales es prácticamente inexistente.

Las crisis alimentarias son también una realidad en África (FAO, 2017). A pesar de que a lo largo de las últimas décadas, la situación de la seguridad alimentaria en la región ha mejorado, la prevalencia de malnutrición - porcentaje de personas cuyo consumo de alimentos habitual es inferior al requerido para mantener una vida activa y saludable - se encuentra aún por encima del $20 \%$. Además, se observa un empeoramiento de los indicadores de malnutrición en los últimos años, lo que parece ser consecuencia, sobre todo, de la existencia de conflictos y de condiciones climáticas adversas (como el fenómeno conocido como El Niño y frecuentes sequías e inundaciones) que habrían derivado en pérdida de cosechas y ganado (FAO, 2017). Esta realidad se manifiesta de forma más acusada en África subsahariana, donde el porcentaje de malnutrición es el más alto del mundo (FAO, FIDA y PMA, 2015).

No es de extrañar, por tanto, que los movimientos migratorios en África se hayan intensificado en las últimas décadas. Según el Informe sobre las Migraciones en el Mundo 2020 (OIM, 2019), desde 2015 los desplazamientos migratorios dentro del continente africano se incrementaron, hasta alcanzar 21 millones de personas desde los 18,5 millones estimados en 2015. Un aumento de similar magnitud se observa en el flujo migratorio hacia fuera del continente, pasando este de los aproximadamente 17 millones de migrantes en 2015 a en torno a 19 millones para el 2019 (OIM, 2019). De entre los continentes de destino, Europa se encuentra en primer lugar, con un total de 10,6 millones de africanos residiendo en Europa en el año 2019 (OIM, 2019).

En este contexto, el objetivo de este artículo es estudiar la influencia de la inseguridad alimentaria en los flujos migratorios desde África a Europa con el objetivo de derivar implicaciones de política económica. En efecto, existe amplia evidencia de que la inseguridad alimentaria estaría en la raíz de una parte sustancial de los flujos migratorios (FAO, 2016). Por ejemplo, se ha encontrado que factores como la escasez de tierra, el hambre o el bajo rendimiento de los cultivos, así como la incapacidad de alimentar a los miembros de una familia (Tegegne y Penker, 2016) o sentimientos de ansiedad en torno a la provisión de alimentos (Regassa y Stoecker, 2011) redundan en una mayor probabilidad de emigrar.

Para este propósito, empleamos una muestra de datos de todos los países de África y Europa durante el período 2000-2018 construida por los propios autores a partir de información procedente de diversos organismos internacionales. La base de datos 
resultante es de tipo bilateral, incluyendo los flujos de migrantes forzados (refugiados, solicitantes de asilo y desplazados internos) de los países considerados, así como información relativa a su estabilidad política, incidencia de desastres naturales o niveles de vida. Como metodología de trabajo, utilizamos modelos de tipo probit. Los resultados nos permiten derivar importantes conclusiones de política pública.

La estructura del artículo es la siguiente. En el apartado 2 se realiza una revisión de la literatura y de los principales conceptos relacionados con las migraciones e inseguridad alimentaria. A continuación, el apartado 3 describe los datos y la metodología empleados en el trabajo. Finalmente, el apartado 4 presenta los resultados y el apartado 5 concluye.

\section{Revisión de la literatura}

\section{Causas de las migraciones}

Son diversas las teorías que a lo largo de las últimas décadas han tratado de encontrar una explicación a la existencia de flujos migratorios. En este sentido, el primer antecedente histórico lo constituye el trabajo de Ravenstein (1885), que trató de identificar y describir una serie de reglas que regulaban la movilidad de personas desde un lugar de origen hacia otro de destino. Casi un siglo más adelante, Everett $\mathrm{S}$. Lee en 1996 desarrollaba su «Teoría de la migración» (Lee, 1996) en la que trataba de explicar las migraciones a través de una serie de factores que se podían categorizar en: $i$ ) los relacionados con el lugar de origen; ii) los relacionados con el lugar de destino; iii) los obstáculos encontrados por el migrante; y iv) factores personales.

Estas contribuciones constituyen la base sobre la que se han construido los denominados modelos de pull-push (Joint Research Center, 2018). De manera general, los modelos de pull-push clasifican los factores que afectan a la decisión de migrar en dos tipos: i) factores de expulsión (o push) —condiciones relacionadas con el país de origen del migrante y que «expulsarían» u obligarían a este a abandonarlo- y ii) de atracción (o pull) —aquellos relacionados con el país de destino, y que atraerían migrantes hacia ciertas localizaciones-. Algunos de los principales factores de push inclurían la pobreza, el desempleo, los conflictos o los desastres naturales. Entre los factores de pull podríamos encontrar algunos como las oportunidades de conseguir un mejor empleo y salario, mejores condiciones de vida y la existencia de libertades políticas y religiosas (Sassen, 2007; Bodvarsson y Van den Berg, 2013, p. 6).

Desde entonces, el estudio de las causas que estarían originando los flujos migratorios ha sido muy extenso. De entre los mismos, los factores económicos se consideran como uno de los principales determinantes de la existencia de migraciones. Desde la perspectiva económica, las migraciones se generan por disparidades geográficas, espaciales y salariales entre las regiones. En este sentido, la diferencia de salarios e ingresos entre los países de origen y destino se ha venido señalando habitualmente como uno de los principales motivos de las migraciones internacionales (OIM, 2018). Para la teoría neoclásica de las migraciones, estas diferencias constituirían, de hecho, la única causa de las migraciones. Sin embargo, investigaciones más recientes apuntan a que la relación entre el ingreso o renta per cápita y las migraciones tiende a ser lo que se denomina humped-shaped, haciendo referencia a la existencia de una relación en forma de $\mathrm{U}$ o «joroba» (hump) entre ambas variables. Es decir, dado que migrar implica una serie de costes para el migrante, las tasas de migración tenderían a aumentar con el nivel de ingreso solo a partir de un cierto nivel de ingreso que se considera de subsistencia, mientras que tenderían a ralentizarse conforme se produce la convergencia entre los ingresos de los países de origen y destino (Lucas, 2006).

La teoría neoclásica y sus posteriores extensiones han sido ampliamente criticadas sobre la base de que reducen la decisión de migrar a un proceso totalmente 
racional basado únicamente en motivos económicos (Borjas, 1989). Sin embargo, se conoce que la decisión de migrar es compleja y que está influenciada por otros factores de índole social, político, cultural, ambiental, sanitario, educativo o religioso, entre otros.

Los conflictos y la inestabilidad política estarían en la base de un importante volumen de flujos migratorios, sobre todo en el caso de los migrantes forzados (Hatton, 2004, 2009). De igual modo, el cambio climático y los desastres naturales se consideran importantes catalizadores de los procesos migratorios. En el caso de los desastres naturales de evolución rápida, como las inundaciones o huracanes, este vínculo se produce de forma más directa. En los denominados "de evolución lenta», como las sequías o el incremento del nivel del mar, la relación con la migración es más indirecta y aparece a través de factores como la pérdida de productividad agraria, incrementos del precio de los alimentos o pérdidas de ingresos y capital (Joint Research Center, 2018).

Otros motivos, como los educativos o de formación de capital humano, los de reunificación familiar -el matrimonio es una importante causa de movilidad entre mujeres de los entornos rurales en los países en desarrollo- y la existencia de redes sociales tanto en el país de origen como de destino que proporcionen apoyo financiero y reduzcan los costes de adaptación al lugar de destino, se consideran también factores importantes en la decisión de migrar (FAO, IFAD, IOM y WFP, 2018).

Por último, cabe mencionar la inseguridad alimentaria, cuya relación con las migraciones será analizada con más detalle posteriormente.

Caracterización de los patrones migratorios: distinción entre migraciones forzadas y voluntarias, $y$ principales dinámicas

Para comprender mejor los movimientos migratorios, una importante distinción es la que se produce entre migraciones voluntarias y forzadas. Dentro de los procesos migratorios, la migración voluntaria hace referencia a aquella que se da en un contexto de paz y seguridad con movimientos migratorios motivados por la búsqueda de mejores condiciones de vida o trabajo (Programa Mundial de Alimentos -PMA-, 2017). La migración forzada, por el contrario, implica el desplazamiento involuntario como medio de supervivencia ante un acontecimiento o situación que pone en peligro la vida y la seguridad del individuo dentro de su país de origen. Por tanto, este tipo de migraciones suelen estar relacionadas con una multiplicidad de circunstancias como la extrema pobreza, catástrofes naturales y climáticas o las guerras o conflictos internos. La migración se concibe en estos casos como la única opción para sobrevivir o escapar de las situaciones anteriormente descritas con el fin de mejorar la calidad y las condiciones de vida (OIM, 2011; FAO, IFAD, OIM y WFP, 2018).

De entre las migraciones forzadas, existen asimismo categorías diferenciadas. De un lado, el estatus de refugiado hace referencia a aquellos individuos reconocidos bajo el amparo de la Convención de Ginebra de 1951, con el Protocolo de 1967 y en conjunto con la Convención de la Organización de la Unidad Africana (OUA) para el gobierno de aspectos específicos de los problemas de los refugiados en África de 1969, además de aquellos reconocidos por el Estatuto de ACNUR (ACNUR, 2017). En efecto, refugiado sería aquel individuo que busca protección en el extranjero debido a fundados temores de ser perseguido por razones como su raza, religión, nacionalidad, opinión pública o pertenencia a un determinado grupo social, o bien por la existencia de conflictos internos, ocupación y dominación extranjera, violación a los derechos humanos o de acontecimientos que perturben gravemente el orden público, y que por estas razones no pueda vivir o permanecer en el país donde reside o que a causa de dichos temores no quiera regresar a él (Gamboa, 2018). Por su parte, la categoría de solicitante de asilo contempla a las personas que han buscado protección internacional, pero 
cuyo estatus de refugiado aún no ha sido resuelto. Se pueden considerar por tanto como una suerte de «casos pendientes» (ACNUR, 2017). Finalmente, los desplazados internos incluirían aquella categoría de migrantes que han experimentado movilizaciones involuntarias dentro de las fronteras del país de origen o residencia habitual a causa de conflictos armados, violencia, persecución, violaciones a los derechos humanos o desastres naturales provocados por el hombre (ACNUR, 2017; OIM, 2011).

Para el caso de la inseguridad alimentaria que nos ocupa en el presente artículo, la migración no puede ser considerada como voluntaria sino como la única opción para escapar de la pobreza y el hambre (FAO, IFAD, IOM y WFP, 2018). Por esta razón, en este artículo centraremos nuestro análisis en el estudio de las migraciones forzadas.

Para finalizar, resulta útil caracterizar las dinámicas más habituales de los patrones migratorios, a fin de entender mejor sus causas. En este sentido, se conoce que la mayor parte de los movimientos migratorios se dan en forma de desplazamientos internos (FAO, IFAD, IOM y WFP, 2018). De estos, gran parte se producen desde áreas rurales hacia áreas urbanas. Se observa, de hecho, que la migración interna es comúnmente un paso intermedio, los migrantes tenderían a movilizarse previamente hacia áreas cercanas con mejores condiciones y solo tras sucesivos desplazamientos tenderían a abordar la inmigración internacional. Esto es sobre todo debido a que migrar internacionalmente implica habitualmente mayores costes, como los derivados del transporte o las barreras legales, mientras que en el caso de la migración interna los costes tienden a ser más reducidos por la existencia de redes sociales más fuertes o la eliminación de barreras culturales e idiomáticas (FAO, IFAD, IOM y WFP, 2018; Hatton, 2004). Incluso para el caso de las migraciones internacionales, algunas teorías aducen que la existencia de vínculos previos entre los países emisores y receptores de migrantes, basadas en factores políticos, culturales o incluso coloniales influyen en la intensidad de estos flujos (Castles y Miller, 2014). Por tanto, es habitual observar que gran parte de los flujos internacionales forzados se producen entre países en desarrollo (FAO, IFAD, IOM y WFD, 2018). Por el contrario, únicamente una pequeña proporción de las solicitudes de asilo se producirían hacia occidente, y de estas no todas se terminan traduciendo en la condición de refugiado (Hatton, 2009).

\section{Seguridad alimentaria y migraciones}

\section{Conceptos básicos sobre seguridad alimentaria}

Según la Cumbre Mundial de la Alimentación de 1996, la seguridad alimentaria «existe cuando todas las personas tienen, en todo momento, acceso físico, social y económico a alimentos suficientes, inocuos y nutritivos que satisfacen sus necesidades energéticas diarias y preferencias alimentarias para llevar una vida activa y sana». Esta definición plantea la identificación de cuatro dimensiones (FAO, 2011):

- La disponibilidad física se relaciona con una adecuada oferta de alimentos para la población. Está vinculada, por tanto, con factores como la producción alimentaria o el comercio.

- El acceso hace referencia a en qué medida la oferta de alimentos disponible termina pudiendo ser consumida por la población. Por tanto, se relaciona más con el ingreso y la capacidad de pago, funcionamiento de los mercados o existencia de desastres naturales y conflictos.

- Utilización. Incluso si los alimentos están disponibles y son accesibles, es posible que la población no realice un buen uso de los mismos, no permitiendo por tanto aprovechar sus nutrientes. Es el caso, por ejemplo, del empleo de prácticas higiénicas inadecuadas que puedan ocasionar problemas gastrointestinales o de una insuficiencia en la diversidad de la dieta.

- Estabilidad. Además de darse las condiciones anteriores, se considera que un individuo no goza de seguridad alimentaria si ese suministro no es estable 
en el tiempo. Factores como la inestabilidad política o la inseguridad económica (e. g. desempleo) influirían en esta dimensión.

La ausencia de un buen funcionamiento en cualquiera de estas cuatro dimensiones es susceptible de originar problemas relacionados con la inseguridad alimentaria que, en caso de agravarse y cronificarse, podrían derivar en una crisis alimentaria.

\section{Efecto sobre las migraciones}

Se conoce que la migración representa una estrategia habitual para escapar a los efectos de la inseguridad alimentaria (FAO, 2016; Concern Worldwide/ Welthungerhilfe, 2000). De hecho, existe amplia evidencia de que la inseguridad alimentaria estaría en la raíz de una parte sustancial de los flujos migratorios rural-urbano (y entre zonas rurales deprimidas y otras zonas rurales más desarrolladas) en los países en desarrollo. Sin embargo, la literatura relacionada con el análisis de los efectos de la seguridad alimentaria sobre las migraciones es aún relativamente escasa.

A este respecto, algunos estudios sugieren que la inseguridad alimentaria ocasionaría migraciones tanto de manera directa como de forma indirecta a través de su influencia en la inestabilidad de los medios de vida y los conflictos. Es el caso del estudio realizado por el Programa Mundial de Alimentos (PMA, 2017), en el que a través de entrevistas con migrantes de África Oriental, África Occidental, Asia y Oriente Medio, entre otros, y la utilización de datos sobre el stock de migrantes a nivel internacional, se concluye que la inseguridad alimentaria, los conflictos y la inestabilidad de los medios de subsistencia a menudo se refuerzan mutuamente, constituyendo determinantes decisivos de la migración internacional únicamente tras múltiples desplazamientos internos previos (PMA, 2017).

Sin embargo, otros estudios señalan que en muchas ocasiones es la propia inseguridad alimentaria, y no los conflictos, la principal causa de la migración. En particular, el estudio Hambre sin Fronteras elaborado de forma conjunta por el Programa Mundial de Alimentos (PMA), la Organización Internacional de las Migraciones (OIM), la Organización de los Estados de América y la London School of Economics and Social Science (LSE), apunta a que en ciertos contextos (como, por ejemplo, Centroamérica) la violencia se halla normalizada y se trata de hecho de una estrategia de subsistencia, por lo que tendría un impacto limitado en decisiones como la de migrar (PMA, OIM y LSE, 2015). Sin embargo, encuentran evidencia de que la inseguridad alimentaria estaría influyendo de forma directa en los desplazamientos ocasionados en los tres países de estudio (Guatemala, Honduras y El Salvador). Una conclusión similar parece alcanzar el informe conjunto de PMA, OIM, BID, FIDA y OEA (2017) a través del análisis del impacto de determinados índices de inseguridad alimentaria sobre la decisión de migrar.

En el contexto africano, existen también numerosas investigaciones que tratan de relacionar la inseguridad alimentaria con los movimientos migratorios, tanto a nivel nacional como regional. Entre ellos merece la pena destacar el informe conjunto de FAO, IFAD, IOM y WFP (2018) que, a través de una revisión exhaustiva de la literatura teórica y empírica reciente, alcanza ciertas conclusiones respecto a la influencia de la inseguridad alimentaria. En relación a este continente, señalan que las hambrunas y situaciones de inseguridad alimentaria son causa directa de movimientos migratorios en la región y que, ante situaciones de crisis alimentaria, los desplazamientos se producirían en primera instancia desde las zonas rurales a las urbanas, a fin de conseguir medios económicos y alimentos para el trayecto antes de emprender el viaje fuera del continente (FAO, IFAD, IOM y WFP, 2018). De igual manera, se apunta a que los patrones migratorios generados en el continente africano tienen a menudo la forma de desplazamientos circulares, es decir, las migraciones tendrían un carácter temporal, retornando posteriormente los migrantes a su lugar de origen para trabajar durante la época de la cosecha (FAO, IFAD, IOM y WFP, 2018). 
Otros estudios han abordado esta cuestión centrándose en los factores socioeconómicos, políticos y culturales que obstaculizan el acceso a la alimentación. En particular, Andrea Pascual Ramos (2014) analiza la situación en África del Este, concluyendo que una de las causas estructurales de la inseguridad alimentaria estriba en los desplazamientos internos de los agricultores por circunstancias como la inadecuada gestión de los recursos naturales, el acceso al agua, la regulación sobre la tenencia de la tierra y la falta de acceso a los mercados, que genera dificultad para la comercialización de la producción.

Desde la perspectiva medioambiental, algunos estudios vinculan los impactos del cambio climático sobre la agricultura con los patrones migratorios y el aumento de los desplazamientos a nivel mundial. A este respecto, Rademacher-Schulz et al. (2014) concluyeron, a través de una investigación mediante encuestas y entrevistas en cuatro comunidades del Distrito de Nadowli (Ghana), que la variabilidad de las precipitaciones estaría incidiendo en el rendimiento de los cultivos, generando problemas de inseguridad alimentaria derivados del incremento en el precio de los alimentos. En este contexto, las migraciones temporales -con un alto componente estacional y en su mayor parte internas o regionalesrepresentarían una estrategia común para paliar los efectos de la inseguridad alimentaria durante las épocas de sequía (Rademacher-Schulz et al., 2014).

En efecto, los resultados de estos trabajos concuerdan con las principales conclusiones del Informe sobre las Migraciones en el Mundo 2020 elaborado por la Organización Internacional de las Migraciones (OIM, 2019), que sugiere que los cambios medioambientales experimentados en África Central $y$ Occidental podrían tener importantes efectos sobre los desplazamientos poblacionales. El informe reconoce además un factor adicional a la hora de comprender los efectos de la inseguridad alimentaria en los movimientos migratorios: el crecimiento poblacional. Un incremento exponencial de la población implica la necesidad de un crecimiento proporcional en la dotación de alimentos. En muchas regiones, esto ha derivado en la intensificación de la producción agrícola, deforestación y estrés hídrico que se traducen, en última instancia, en un incremento de la inseguridad alimentaria y deterioro de las condiciones de vida (OIM, 2019). La migración surgiría entonces como una estrategia para afrontar la situación de inseguridad alimentaria (Pérez de Armiño, 2011).

En definitiva, podemos concluir que hasta el momento la literatura relativa al análisis de la influencia de la inseguridad alimentaria sobre los flujos migratorios en África se ha centrado sobre todo en los movimientos migratorios rurales-urbanos, o en un contexto transnacional/intrarregional dentro del continente africano. Sin embargo, el análisis de los flujos migratorios hacia fuera de África, y en particular hacia Europa, que es el objeto de nuestro análisis, no ha recibido tanta atención.

\section{Datos y estrategia empírica}

\section{Datos, variables y muestra}

El objetivo del artículo es analizar el efecto de las crisis alimentarias en los flujos migratorios entre África y Europa. Para este propósito, nuestro trabajo de investigación se basa en una muestra de datos de 97 países, entre los cuales se incluyen los 54 pertenecientes al continente africano (46 pertenecientes a África subsahariana y 8 al resto de África) y los 43 países europeos (27 de la UE y 16 del resto de Europa) ${ }^{2}$, para el período 2000-2018. El Cuadro 1 ofrece un listado de todos los países incluidos, clasificados por subregiones.

La información empleada proviene de fuentes muy diversas, que han sido recopiladas directamente por los autores. Estas fuentes, así como la descripción de las variables empleadas y sus unidades de medida se resumen en el Cuadro 2.

\footnotetext{
2 Dados los recientes acontecimientos relacionados con la salida del Reino Unido de la UE, este ha sido excluido como país perteneciente al conjunto de la UE para todo el período.
} 


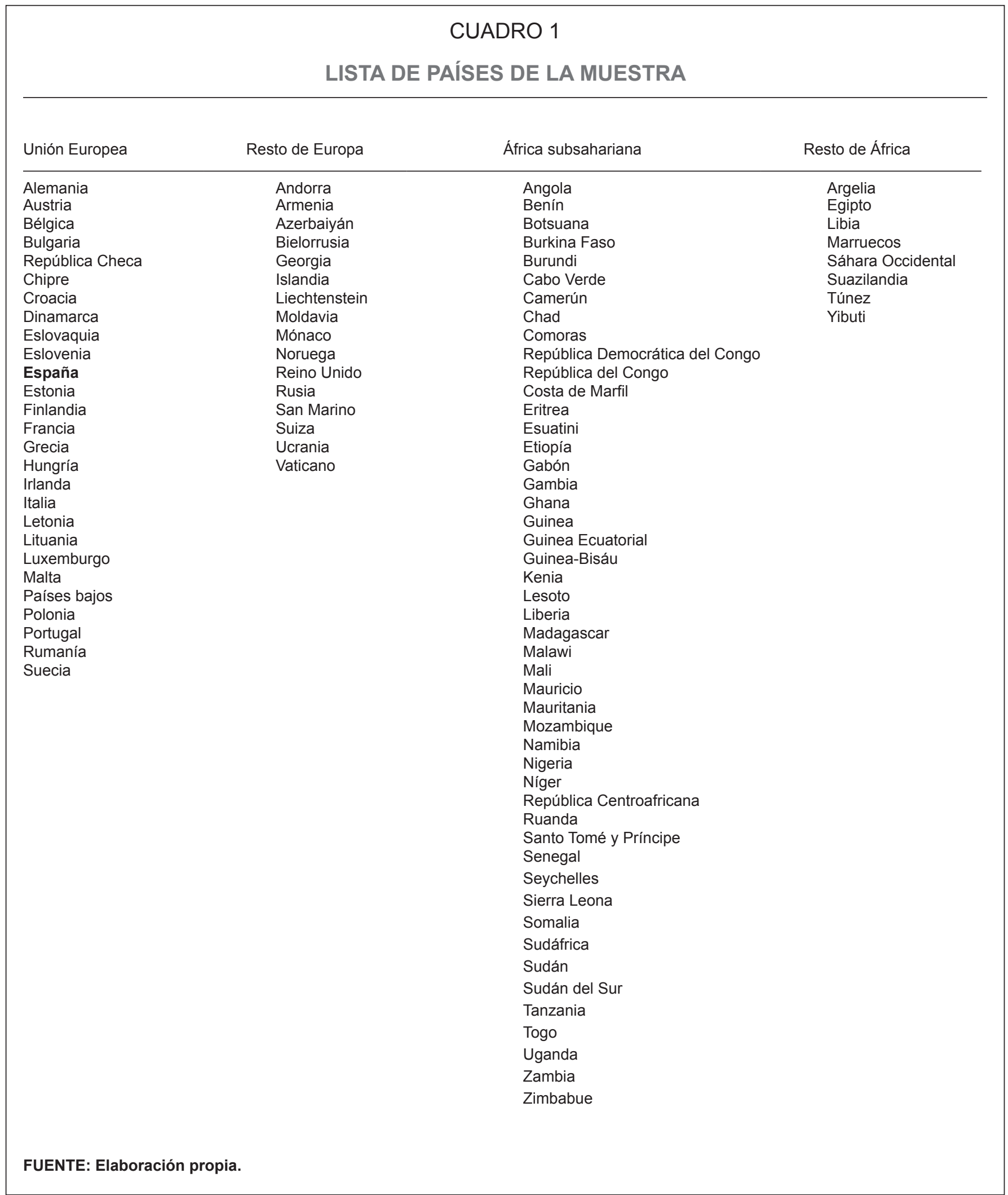




\section{CUADRO 2}

\section{VARIABLES: DESCRIPCIÓN Y FUENTES}

Variable Descripción Fuente

\section{Desplazamientos forzados}

Refugiados

Solic_asilo

IDPS

Refugiados_binaria

Asilo_binaria

Inseguridad3
Inseguridad2

Inseguridad1
Número de refugiados.

Número de solicitantes de asilo (personas).

Número de desplazados internos (personas).

Variable binaria que toma valor 1 cuando el flujo de refugiados de un país a otro en un determinado año es positivo; 0 en caso contrario.

Variable binaria que toma valor 1 cuando el flujo de solicitantes de asilo de un país a otro en un determinado año es positivo; 0 en caso contrario.

\section{Inseguridad alimentaria}

Variable binaria que toma el valor 1 cuando el país se encuentra en una situación de «déficit excepcional de producción o de los suministros totales de alimentos» según FAO y 0 en caso contrario. Para origen y destino, respectivamente.

Variable binaria que toma el valor 1 cuando el país se encuentra en una situación de «inseguridad alimentaria grave pero localizada» según FAO y 0 en caso contrario.

Variable binaria que toma el valor 1 cuando el país se encuentra en una situación de «ausencia generalizada de acceso a alimentos» según FAO y 0 en caso contrario.
Alto Comisionado de las Naciones Unidas para los Refugiados (ACNUR).

Alto Comisionado de las Naciones Unidas para los Refugiados (ACNUR).

Alto Comisionado de las Naciones Unidas para los Refugiados (ACNUR).

Elaboración propia.

Elaboración propia.

FAO (Food and Agriculture Organization).

FAO (Food and Agriculture Organization).

FAO (Food and Agriculture Organization).

Banco Mundial. de origen, en paridad del poder adquisitivo (PPA).

PIB per cápita en dólares internacionales de 2011, PPA.

Número de muertes totales en desastres naturales.

Desastresnat $n^{\circ}$ muertes

Indicador de estabilidad política y ausencia de violencia o terrorismo para el país de origen. El dato del Banco Mundial estima una puntuación en el indicador agregado, en unidades de una distribución normal estándar, que va entre $-2,5$ y 2,5 aproximadamente.

Indicador de estabilidad política y ausencia de violencia o terrorismo para el país de origen. Mismas características que el de origen.

\section{Banco Mundial.}

Base de datos internacional sobre desastres naturales EM-DAT.

Banco Mundial.

Banco Mundial.

FUENTE: Elaboración propia. 
Los datos sobre migraciones forzadas provienen del Alto Comisionado de las Naciones Unidas para los Refugiados (ACNUR). En particular, se ha tomado información sobre el número de refugiados (refugiados), solicitantes de asilo (solic_asilo) y desplazados internos (IDPS). Con respecto a las variables relacionadas con la existencia de crisis alimentarias, FAO (Food and Agriculture Organization u Organización de las Naciones Unidas para la Alimentación y la Agricultura) publica de forma regular una lista de países que necesitan ayuda alimentaria externa debido a la carencia de recursos para hacer frente a situaciones de inseguridad alimentaria. Esta información forma parte del SIMA (Sistema Mundial de Información y Alerta sobre la Alimentación y la Agricultura, SMIA, por sus siglas en inglés), que tiene por objeto supervisar indicadores claves de oferta y demanda de alimentos para evaluar la situación y alertar de forma temprana sobre la existencia de crisis alimentarias en determinados países o regiones. La lista de «países en necesidad de ayuda alimentaria externa» se actualiza cuatro veces al año, y clasifica a los países en tres niveles: $i$ ) déficit excepcional de producción o de los suministros totales de alimentos; ii) inseguridad alimentaria grave pero localizada; y iii) ausencia generalizada de acceso a alimentos. Para transformar esta lista en observaciones anuales en concordancia con las estadísticas de migración forzada, se generan respectivamente tres variables, que tratan de reflejar qué crisis ha sido la de mayor prevalencia a lo largo del año estudiado, considerando siempre la de mayor nivel en caso de contar con el mismo número de apariciones en los informes/ listas. Estas variables toman los nombres de inseguridad1, inseguridad2 e inseguridad 3 y reflejan respectivamente la prevalencia de los tres niveles comentados con anterioridad.

Finalmente, para conocer el efecto de las crisis alimentarias en los patrones migratorios ha de controlarse por una serie de variables que también pueden influirlos de forma potencial. Se conoce que las catástrofes naturales suelen estar en la raíz de numerosos movimientos migratorios (PMA, OIM, BID, FIDA y OEA, 2017). Por tanto, se ha incluido el número de muertes en desastres naturales (desastrenat_ $n^{\circ}$ muertes) procedente de la «Base de datos internacional sobre desastres naturales EM-DAT», elaborada por el Centro de Investigación en Epidemiología de los Desastres Naturales (CRED, por sus siglas en inglés). De igual modo, los conflictos y la inestabilidad política son una causa habitual de migraciones (PMA, 2017). Para tener en cuenta la posible existencia de inestabilidad política en los países estudiados, hemos empleado el índice de «Estabilidad política y Ausencia de violencia/terrorismo» (estab_política_ orig y estab_política_dest), elaborado por Banco Mundial. Finalmente, las diferencias en el nivel socioeconómico de los países son recogidas a través de la variable PIB per cápita en dólares internacionales de 2011, en paridad del poder adquisitivo (PIBpc_orig y PIBpc_dest).

La base de datos resultante es de carácter bilateral, es decir, para cada observación (número de refugiados, desplazados, etc.) se registra el país de origen y destino de los migrantes forzados, así como el año y características socioeconómicas y de seguridad alimentaria de ambos países. De este modo, el número total de observaciones para los flujos migratorios entre África y Europa considerando los 19 años de la muestra es de 88.236. A esto hay que añadir los datos de migraciones forzadas dentro del continente africano, ya sean en forma de desplazamientos internos, para los cuales el país de origen es igual al país de destino (1.026 flujos bilaterales), o migraciones intrarregionales dentro de África, por un total de 55.404 observaciones adicionales para el total de los 19 años de la muestra.

El Cuadro 3 muestra los principales estadísticos descriptivos de las variables incluidas en nuestro estudio.

Como se puede observar, los países incluidos en la muestra son muy diversos en términos de renta per cápita y estabilidad política o ausencia de violencia/ 
CUADRO 3

ESTADÍSTICOS DESCRIPTIVOS DE LAS VARIABLES

\begin{tabular}{|c|c|c|c|c|c|}
\hline Variables & $\begin{array}{c}\text { Número de } \\
\text { observaciones }\end{array}$ & Media & Desviación típica & Mínimo & Máximo \\
\hline IDPs (desplazados) & 1.026 & 110.071 & 432.682 & 0 & 4.516 .865 \\
\hline Solic_asilo & 88.236 & 20,81 & 329,0 & 0 & 37.967 \\
\hline Refugiados & 88.236 & 68,01 & 801,8 & 0 & 55.334 \\
\hline PIBpc_orig & 76.779 & 18.460 & 19.082 & 545,3 & 97.864 \\
\hline PIBpc_dest & 76.779 & 18.460 & 19.082 & 545,3 & 97.864 \\
\hline Estab_política_orig & 77.191 & 0,0415 & 0,996 & $-3,315$ & 1,755 \\
\hline Estab_política_dest & 77.191 & 0,0415 & 0,996 & $-3,315$ & 1,755 \\
\hline Inseguridad1_orig & 88.236 & 0,0171 & 0,129 & 0 & 1 \\
\hline Inseguridad2_orig & 88.236 & 0,0721 & 0,259 & 0 & 1 \\
\hline Inseguridad3_orig & 88.236 & 0,0414 & 0,199 & 0 & 1 \\
\hline Inseguridad1_dest & 88.236 & 0,0171 & 0,129 & 0 & 1 \\
\hline Inseguridad2_dest & 88.236 & 0,0721 & 0,259 & 0 & 1 \\
\hline Inseguridad3_dest & 88.236 & 0,0414 & 0,199 & 0 & 1 \\
\hline Desastrenat_nmuertes & 88.236 & 180,0 & 1.696 & 0 & 56.100 \\
\hline Asilo_binaria & 88.236 & 0,136 & 0,343 & 0 & 1 \\
\hline Refugiados_binaria & 88.236 & 0,181 & 0,385 & 0 & 1 \\
\hline
\end{tabular}

FUENTE: Elaboración propia.

terrorismo, variando entre países que se encuentran entre los de mayor renta per cápita a nivel internacional, principalmente los situados en la UE, y los de menores niveles de renta y estabilidad política más concentrados en África, y en particular, África subsahariana. Ocurre de igual modo con la incidencia de desastres naturales, con valores que van desde la ausencia de estos hasta 56.100 muertes por este motivo en Rusia en el año 2010. En este caso, sin embargo, no existe necesariamente un patrón regional tan característico, los países azotados por este tipo de desastres se encuentran repartidos por ambos continentes. El número de refugiados, solicitudes de asilo y desplazados internos, así como los niveles de inseguridad alimentaria será analizado con mayor profundidad en el subapartado que viene a continuación.
Análisis de los patrones de migraciones forzadas en el continente africano, y entre África y Europa. Relación con el nivel de inseguridad alimentaria

El Gráfico 1A y 1B nos muestra la evolución de los patrones migratorios forzados con origen en África y destino en Europa (Gráfico 1A) o dentro del propio continente africano (Gráfico 1B). En ellos es posible observar una tendencia creciente en el número de migraciones forzadas con origen en el continente africano desde el año 2000 hasta la actualidad, ya sea en forma de desplazamientos nacionales, intrarregionales o internacionales hacia la UE. El Gráfico 1B muestra que, mientras que en el año 2000 la cifra de desplazados forzados con origen en África que habían sido acogidos por un país perteneciente al continente africano ascendía 

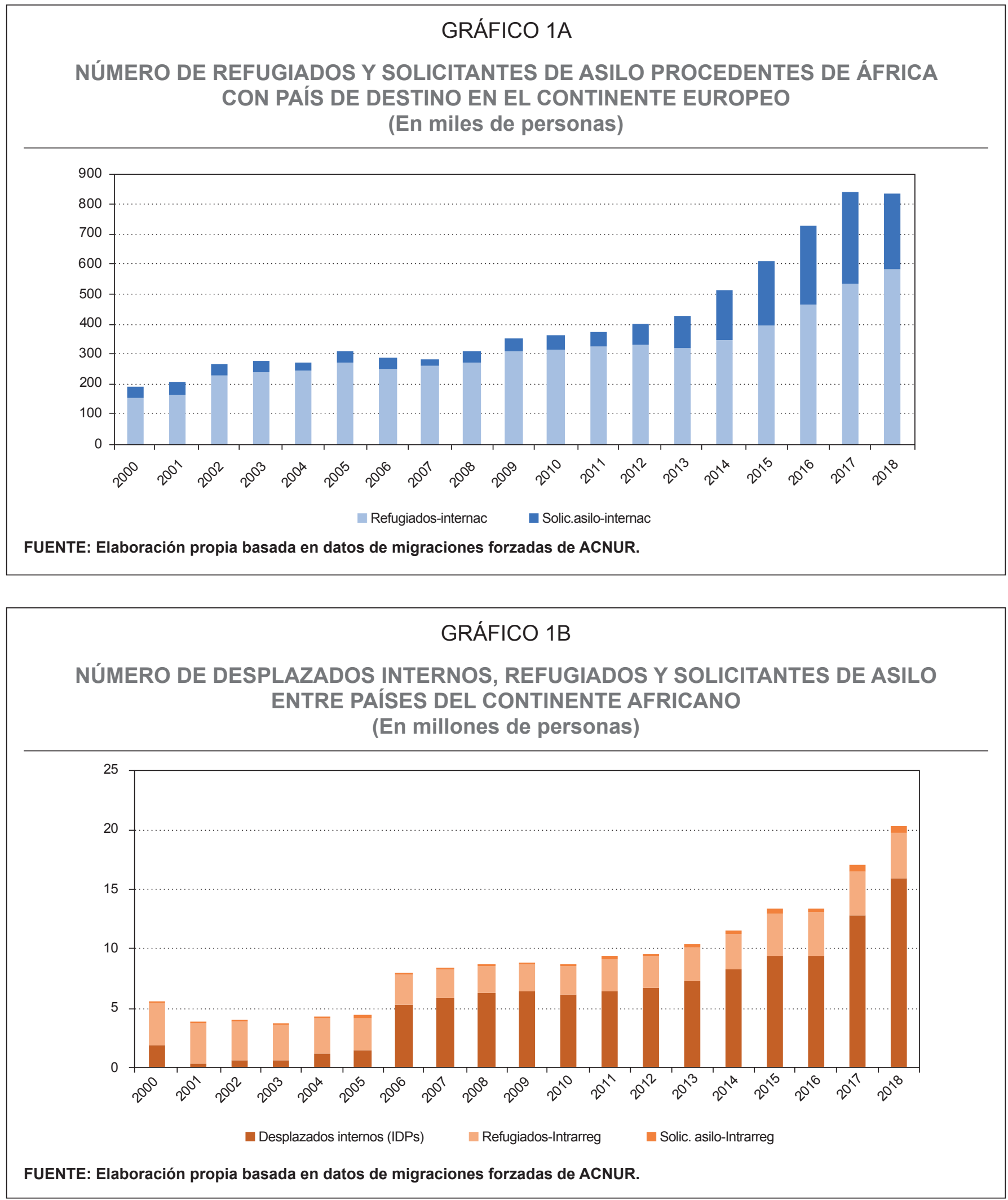
a 5,5 millones, para finales de 2018 el número total de desplazados forzados se situaba en torno a 20 millones de personas. De estos, cerca de 16 millones supondrían desplazamientos internos (movimientos en el interior de los propios países) y algo más de 4 millones corresponderían a desplazamientos hacia otros países africanos a través de solicitudes de asilo o como refugiados. A pesar de que la mayor parte de migrantes forzados con origen en África permanecen dentro del continente, los flujos internacionales, y en particular hacia Europa, que es la región en la que se centra el análisis de este estudio, tampoco son despreciables. EI Gráfico 1A ilustra que, a finales de 2018, el número total de desplazados forzados de origen africano que habían sido acogidos por un país europeo o se hallaban esperando respuesta a su solicitud de asilo ascendía a las 834.000 personas, habiéndose por tanto multiplicado prácticamente por cuatro desde el año 2000 , en el que la cifra ascendía a cerca de 190.000.

La desagregación de estos flujos por regiones de origen y de destino nos proporciona más información sobre la composición de los mismos (ver Gráfico 2). El análisis desagregado de los flujos migratorios con destino en Europa nos desvela que, durante el período 2000-2018, la mayor parte de los refugiados y solicitantes de asilo (hasta un $94 \%$ ) proceden de África subsahariana, y el $72 \%$ del total de estos migrantes forzados son acogidos por países integrantes de la UE. Es decir, la Unión Europea mantuvo durante todo el período un stock medio de 213.222 refugiados y 84.136 solicitantes de asilo, mientras que el resto de Europa acogió únicamente 102.550 refugiados y mantuvo 12.372 solicitantes de asilo de media. Respecto a las migraciones intrarregionales (dentro del continente africano), de nuevo se observa que la mayor parte de los solicitantes de asilo y refugiados proceden de África subsahariana y son, en su mayoría, acogidos por otros países de África subsahariana. De igual modo sucede con la cifra de desplazados internos, para los que la práctica totalidad se encuentra en África subsahariana.
Centrándonos ahora en las migraciones internacionales desde África a Europa, el Gráfico 3 muestra los diez principales destinos y orígenes de estas migraciones. Mientras que en cifras absolutas los principales receptores europeos de migrantes forzados con origen en África son Alemania, Reino Unido, Italia y Francia, la imagen cambia radicalmente cuando se estudia el número medio de migrantes acogidos en relación a la población media del país durante el período. Bajo este criterio, Malta, Noruega, Suiza y Suecia serían los que han realizado un mayor esfuerzo receptor de desplazados forzados procedentes de África. En el caso de los países de origen de los migrantes la posición de los países no varía demasiado, independientemente del criterio utilizado. Los países con más desplazados forzados en el continente europeo serían Eritrea (con en torno a un 2,34 \% de su población desplazada en Europa de media durante el período estudiado), Somalia o el Congo.

Finalmente, la caracterización de estos flujos (entre África y Europa) en función del nivel de inseguridad alimentaria nos permite obtener una primera panorámica sobre la relación entre crisis alimentarias y migraciones forzadas. Como se observa en el Gráfico 4, la media del stock de refugiados emitido hacia Europa por los países africanos que se encuentran sometidos a algún tipo de crisis alimentaria es superior que aquellos que no sufren ningún tipo de crisis, y se incrementa con el nivel de intensidad de la crisis alimentaria.

\section{Estrategia metodológica}

El objeto de nuestro análisis en este artículo es entender la influencia de las crisis alimentarias en los patrones de desplazamientos forzados entre África y Europa. A pesar de que los resultados del análisis descriptivo parecen indicar que las crisis alimentarias en los países de origen podrían incrementar los desplazamientos forzados hacia Europa, existen muchos factores que podrían confundir nuestro análisis. Por ejemplo, podría darse el caso de que algunos de los países se 


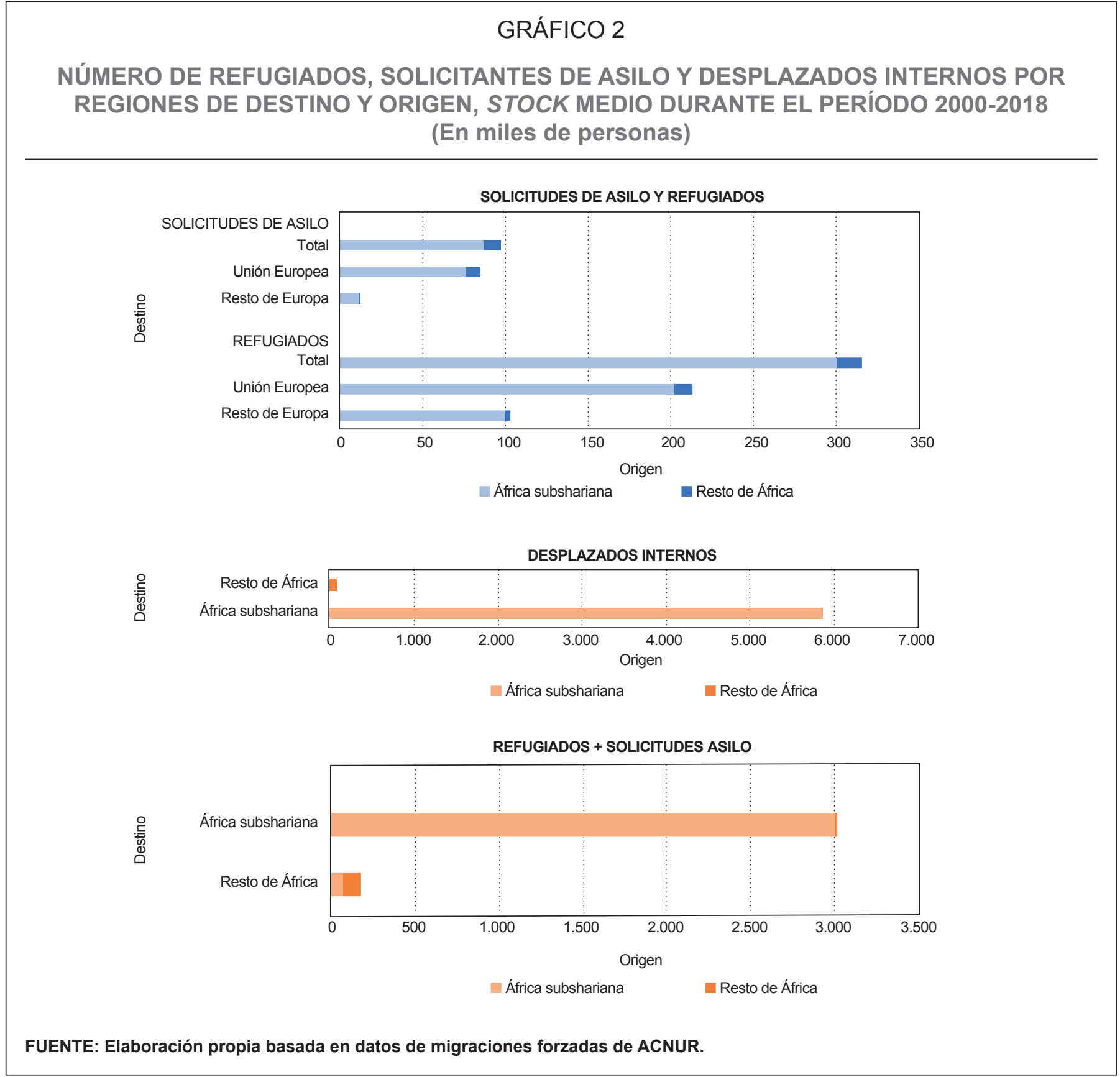

encuentren simultáneamente en una situación de crisis alimentaria y un conflicto bélico o desastre natural, de forma que sean estos últimos, y no la crisis alimentaria la que esté ocasionando estos desplazamientos.

Para controlar todos estos factores, el presente estudio utiliza como metodología de trabajo un ejercicio basado en el análisis econométrico. Un estudio más pormenorizado de los estadísticos descriptivos incluidos en el Cuadro 3 nos ofrece información adicional útil para decidir el enfoque del análisis. En particular, las variables asilo_binaria y refugiados_binaria toman el valor 1 cuando, para un año concreto, el stock de 


\section{GRÁFICO 3}

\section{RANKING DE LOS PRINCIPALES PAÍSES DE ORIGEN Y DESTINO POR EL NÚMERO TOTAL DE REFUGIADOS + SOLICITANTES DE ASILO, STOCK MEDIO DURANTE EL PERÍODO 2000-2018}
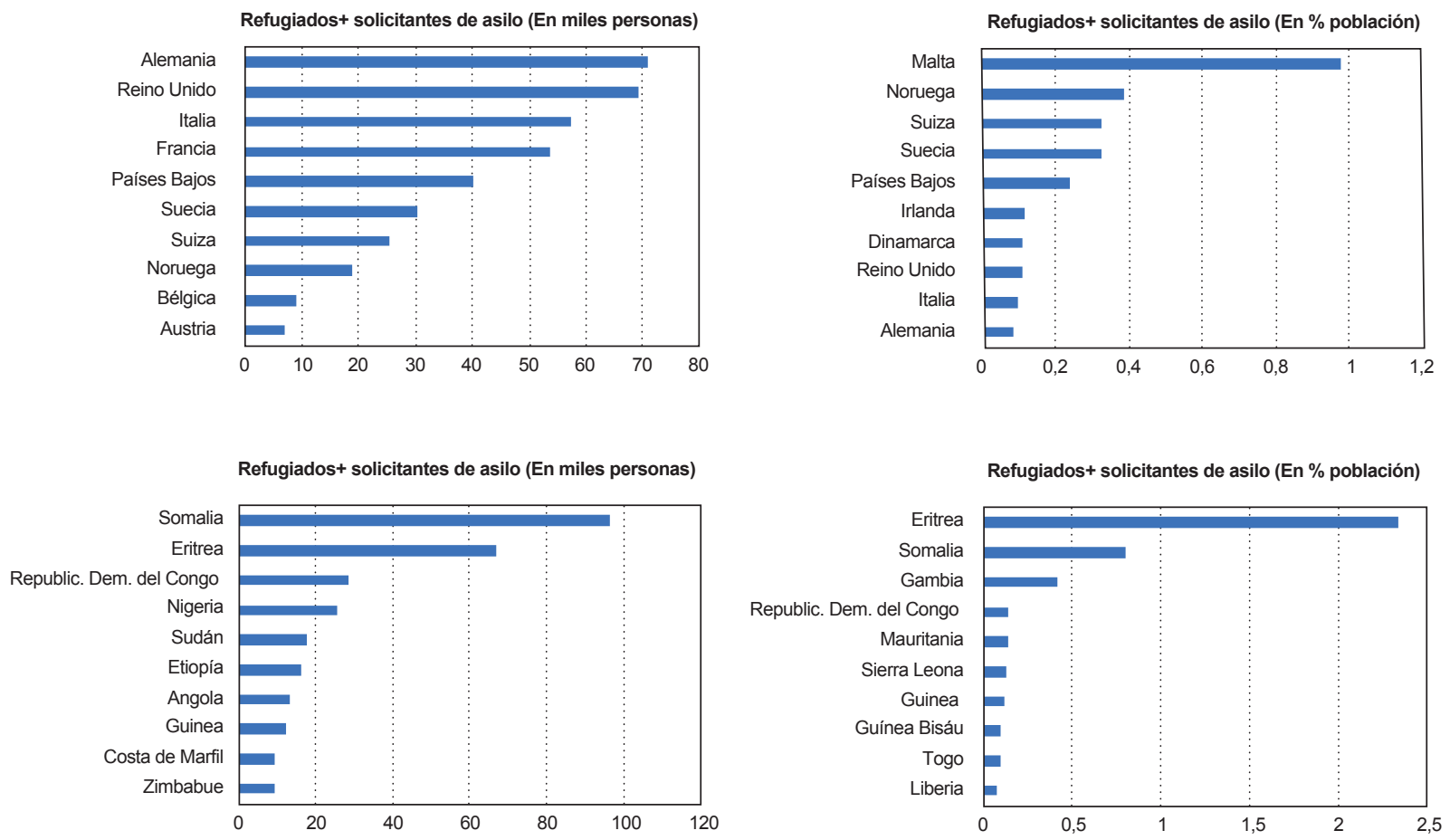

FUENTE: Elaboración propia basada en datos de migraciones forzadas de ACNUR.

desplazados forzados con un determinado país de origen y de destino es positivo, y 0 cuando para ese año el flujo es cero/nulo. La media de estas variables (Cuadro 3) nos indica que únicamente en el 13,6 \% de los casos existe un stock positivo de refugiados, siendo esta cifra del 18,1\% para el caso de las solicitudes de asilo. Es decir, cuando nos centramos en los desplazamientos forzados entre África y Europa, para la mayor parte de las combinaciones de país de origen, destino y año, el stock de desplazados es nulo.

Constatando esta realidad, queremos estudiar qué determina la probabilidad de que en un determinado año, un país europeo (de destino) tenga en acogida refugiados -0 esté tramitando solicitudes de asilo- procedentes de un determinado país africano, frente a aquellos que no lo tienen. En particular, queremos estudiar cómo incide la existencia de crisis alimentarias de distinto nivel en la probabilidad de que exista (o no) stock de refugiados y solicitantes de asilo entre cada par de países.

Para ello, utilizamos un modelo probit. En este tipo de modelos, la variable dependiente es una variable binaria como la descrita anteriormente (toma valores 0 o 1), que representa la probabilidad de que ocurra un determinado suceso (en nuestro caso, la probabilidad de que el stock de migrantes forzados entre dos países en un año determinado sea positivo o distinto de cero). Los modelos de tipo probit se derivan 


\section{GRÁFICO 4}

\section{STOCK MEDIO ANUAL DE REFUGIADOS Y SOLICITANTES DE ASILO DE LOS PAÍSES DE ORIGEN, SEGÚN EL NIVEL DE CRISIS ALIMENTARIA. FLUJOS MIGRATORIOS ENTRE ÁFRICA Y ESPAÑA PARA EL PERÍODO 2000-2018}

(En personas)

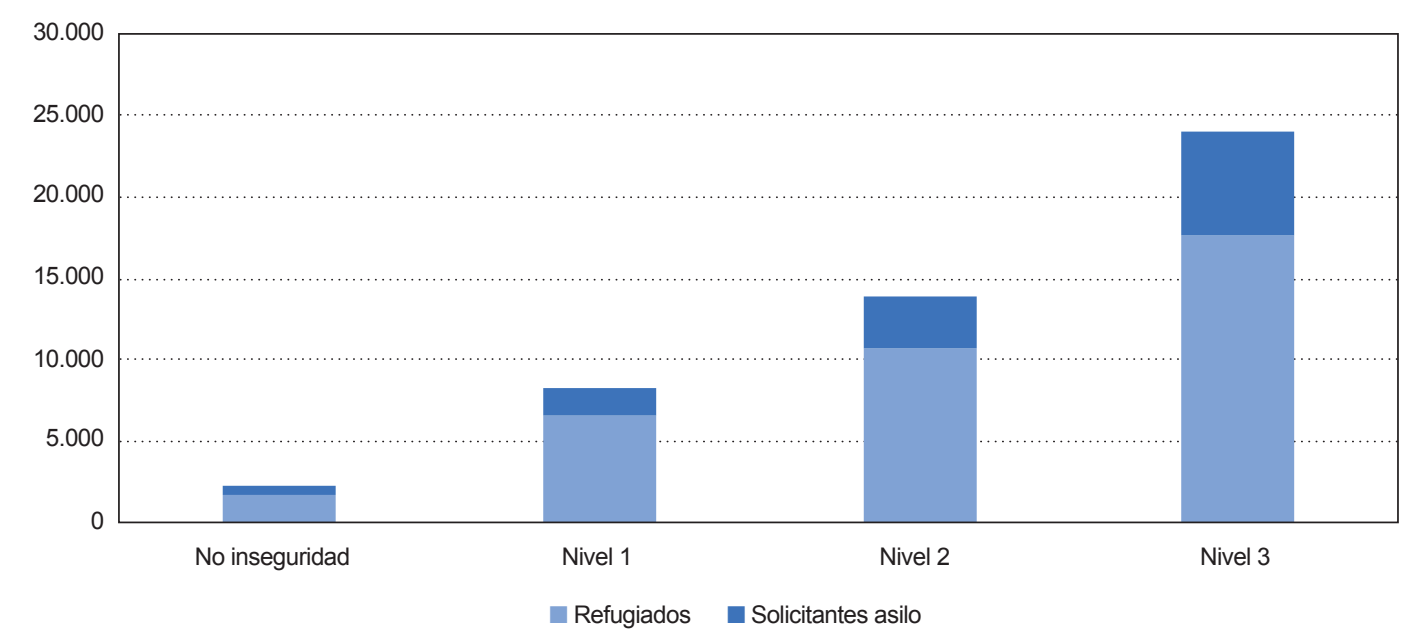

FUENTE: Elaboración propia basada en datos de ACNUR y FAO.

de la existencia de una variable latente o inobservada subyacente que establece una relación lineal con las variables cuya influencia se pretende analizar:

$Y_{i j}^{*}=\alpha+\beta$ Inseguridad $_{i}+\delta$ Inseguridad,$+\mu X_{i}+\sigma X_{j}+\varepsilon_{i j}[1]$

En este estudio, la variable latente podría considerarse la utilidad social percibida de mantener un determinado stock de solicitantes de asilo, refugiados o desplazados internos con origen en el país $i$ y destino en el país $j$, respectivamente (la denominaremos como $Y_{i j}^{*}$ ). Esta utilidad social dependería asimismo de un conjunto de variables socioeconómicas de control para los países de origen $\left(X_{i}\right)$ y destino $\left(X_{i}\right)$, en las que se incluyen el PIB per cápita en el país de origen (PIBpc_orig) y destino (PICpc_dest), el número de muertes en desastres naturales (desastrenat_ $n^{\circ}$ muertes), y el nivel de estabilidad política en origen (estab_política_orig) y destino (estab_política_dest). Por último, se considera el conjunto de variables de interés para nuestro estudio, relacionadas con los niveles de inseguridad

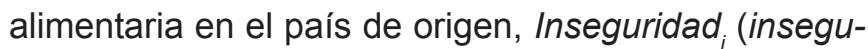
ridad1_orig, inseguridad2_orig e inseguridad3_orig) y destino, Inseguridad (inseguridad1_dest, inseguridad2_dest e inseguridad3_dest). El error se asume distribuido de forma normal.

La utilidad social de mantener un stock de refugiados es difícil de medir. Sin embargo, sí que es posible observar si existe o no ese stock, asumiendo que los países tenderán a acoger -i. e. mantener un stock positivo- de migrantes forzados si la utilidad social es percibida como positiva, mientras que si esta es percibida como negativa o nula, la acogida de migrantes forzados será también nula.

$$
Y= \begin{cases}1, & Y^{*}>0 \\ 0, & Y^{*} \leq 0\end{cases}
$$


Por tanto, la variable binaria objeto de estudio queda definida de forma que tome el valor 0 si el número de migrantes forzados (refugiados, solicitantes de asilo o desplazados internos) es igual a cero, y 1 si el número de migrantes forzados es positivo. Así, la probabilidad de que en un año determinado, exista un stock positivo de las diferentes categorías de migrantes forzados puede ser descrita como:

$$
\operatorname{Prob}(Y=1 \mid X)=\operatorname{Pr}\left(Y^{*}>0 \mid X\right)
$$

Esta probabilidad se obtiene a través de una distribución normal acumulada estándar. Para más información sobre los modelos probit, se puede consultar entre otros Wooldridge (2010) o Greene (2018).

\section{Resultados y discusión}

Los resultados de los diversos modelos probit para los migrantes forzados se encuentran en el Cuadro 4. Los modelos 1 y 2 recogen, respectivamente, el resultado de las estimaciones de la probabilidad de que exista un stock de solicitantes de asilo (Modelo 1) y refugiados (Modelo 2) ${ }^{3}$ con origen en un país africano y destino en Europa, constituyendo por tanto el principal objetivo de nuestro análisis.

De forma general, los resultados muestran que la probabilidad de que exista cierto stock de migrantes forzados depende del nivel de seguridad alimentaria. En particular, los niveles de inseguridad alimentaria 2 y 3 en origen, es decir, de los tipos «inseguridad alimentaria severa pero localizada» y "falta de acceso generalizada», predicen una mayor probabilidad de migrantes forzados (tanto refugiados como solicitantes de asilo) entre África y Europa, como se deduce del coeficiente positivo y altamente significativo de estas variables en

\footnotetext{
3 En el modelo 2, la variable insecure1_dest no está incluida. Esto es porque predice perfectamente el fallo (valor cero de la variable binaria) y, por tanto, ha de ser eliminada del modelo.
}

\section{CUADRO 4}

MODELOS PROBIT PARA LA

PROBABILIDAD DE EXISTENCIA

DE DESPLAZAMIENTOS INTERNOS,

FLUJOS DE SALIDA DE REFUGIADOS Y SOLICITANTES DE ASILO

\begin{tabular}{|c|c|c|}
\hline \multicolumn{3}{|c|}{ Entre África-Europa } \\
\hline & $\begin{array}{l}\text { Prob_solicitantes } \\
\text { asilo }\end{array}$ & Prob_refugiados \\
\hline Desastrenat_n'muertes & $\begin{array}{c}2,13 e-06 \\
(4,79 e-06)\end{array}$ & $\begin{array}{l}5,64 \mathrm{e}-06 \\
(4,45 \mathrm{e}-06)\end{array}$ \\
\hline PIBpc_orig & $\begin{array}{l}-1,40 \mathrm{e}-05^{\star * *} \\
(8,84 \mathrm{e}-07)\end{array}$ & $\begin{array}{l}-2,34 \mathrm{e}-05^{\star * *} \\
(9,29 \mathrm{e}-07)\end{array}$ \\
\hline PIBpc_dest & $\begin{array}{l}1,94 \mathrm{e}-05^{\star * *} \\
(4,81 \mathrm{e}-07)\end{array}$ & $\begin{array}{l}1,92 \mathrm{e}-05^{\star * *} \\
(4,65 \mathrm{e}-07)\end{array}$ \\
\hline Estab_política_orig & $\begin{array}{l}-0,403^{* * *} \\
(0,00942)\end{array}$ & $\begin{array}{l}-0,483^{* * *} \\
(0,00929)\end{array}$ \\
\hline Estab_política_dest & $\begin{array}{c}0,109^{* * *} \\
(0,0130)\end{array}$ & $\begin{array}{c}0,163^{* * *} \\
(0,0128)\end{array}$ \\
\hline Inseguridad1_orig & $\begin{array}{r}0,0638^{*} \\
(0,0384)\end{array}$ & $\begin{array}{l}-0,136^{\star * *} \\
(0,0379)\end{array}$ \\
\hline Inseguridad2_orig & $\begin{array}{c}0,234^{* * *} \\
(0,0208)\end{array}$ & $\begin{array}{l}0,105^{\star \star *} \\
(0,0207)\end{array}$ \\
\hline Inseguridad3_orig & $\begin{array}{c}0,301^{* * *} \\
(0,0274)\end{array}$ & $\begin{array}{l}0,0740^{* * *} \\
(0,0273)\end{array}$ \\
\hline Inseguridad1_dest & $\begin{array}{l}-1,209^{* * *} \\
(0,303)\end{array}$ & \\
\hline Inseguridad2_dest & $\begin{array}{l}-0,594^{\star * *} \\
(0,0770)\end{array}$ & $\begin{array}{l}-1,023^{* \star *} \\
(0,110)\end{array}$ \\
\hline Inseguridad3_dest & $\begin{array}{l}-0,888^{* * *} \\
(0,147)\end{array}$ & $\begin{array}{l}-1,446^{* * *} \\
(0,246)\end{array}$ \\
\hline Constante & $\begin{array}{l}-1,527^{* * *} \\
(0,0185)\end{array}$ & $\begin{array}{l}-1,229^{\star * *} \\
(0,0175)\end{array}$ \\
\hline Observations & 66.446 & 65.124 \\
\hline Test de Wald & 17.426 & 23.517 \\
\hline (p-valor) & 0,00 & 0,00 \\
\hline Log-pseudoverosimilitud & -20.353 & -21.723 \\
\hline Pseudo-R2 & 0,300 & 0,351 \\
\hline
\end{tabular}


todos los modelos estimados. Por su parte, la inseguridad alimentaria de tipo 1 («déficit excepcional de producción o de los suministros totales de alimentos») afecta de forma distinta. Mientras parece estar relacionada con una mayor probabilidad de que existan solicitudes de asilo intercontinentales, no ocurre lo mismo con la probabilidad de existencia de refugiados. Esto sería consistente con los trabajos que señalan que de las solicitudes de asilo recibidas por occidente, solo una parte se traducen a la condición de refugiado (Hatton, 2009). Sería de esperar, por tanto, que los países receptores estén más dispuestos a aceptar solicitudes de asilo (pasando así al estatus de refugiado) cuando la situación de inseguridad alimentaria en los países de origen reviste cierto nivel de gravedad, mientras que sean menos proclives frente a aquellas situaciones en las que la inseguridad alimentaria es únicamente un déficit excepcional (nivel 1). De otro lado, como cabría esperar los distintos niveles de insegu$\mathrm{ridad} / \mathrm{crisis}$ alimentaria en el país de destino predicen una menor probabilidad de tener en acogida migrantes forzados (signo negativo y significativo) para todas las categorías consideradas. Debe ser destacado, así mismo, que la magnitud de este efecto es incluso superior a la generada por la inseguridad alimentaria en origen.

De los resultados obtenidos es posible, por tanto, concluir que la seguridad alimentaria es relevante a la hora de explicar la existencia de stocks de migrantes forzados entre África y Europa, incluso una vez el resto de factores habituales, como conflictos, inestabilidad política, desastres naturales o los niveles de ingreso, hayan sido tenidos en cuenta. Sin embargo, los coeficientes de un modelo probit no pueden ser interpretados de forma directa como efectos marginales. Por tanto, para determinar la magnitud de la respuesta de la variable dependiente (la probabilidad de que haya un stock positivo de cada grupo de migrantes forzados) ante un cambio en las variables de interés (relacionadas con la seguridad alimentaria), han de calcularse los efectos marginales. En este artículo, reportamos directamente las elasticidades, es decir, el cambio porcentual en la variable dependiente ante un cambio/incremento de un $1 \%$ en la

\begin{tabular}{|c|c|c|}
\hline \multicolumn{3}{|c|}{$\begin{array}{l}\text { ELASTICIDADES DERIVADAS DE } \\
\text { LOS MODELOS DEL CUADRO } 4\end{array}$} \\
\hline \multicolumn{3}{|c|}{ Entre África-Europa } \\
\hline & $\begin{array}{l}\text { Prob_solicitantes } \\
\text { asilo }\end{array}$ & Prob_refugiados \\
\hline Desastrenat_nomuertes & $\begin{array}{c}0,000790 \\
(0,00178)\end{array}$ & $\begin{array}{c}0,00201 \\
(0,00159)\end{array}$ \\
\hline PIBpc_orig & $\begin{array}{l}-0,515^{\star * *} \\
(0,0338)\end{array}$ & $\begin{array}{l}-0,817^{\star \star *} \\
(0,0355)\end{array}$ \\
\hline PIBpc_dest & $\begin{array}{l}0,712^{* * *} \\
(0,0183)\end{array}$ & $\begin{array}{c}0,693^{* \star *} \\
(0,0177)\end{array}$ \\
\hline Estab_política_orig & $\begin{array}{l}-0,0333^{\star * *} \\
(0,000823)\end{array}$ & $\begin{array}{l}-0,0287^{\star \star \star} \\
(0,000609)\end{array}$ \\
\hline Estab_política_dest & $\begin{array}{l}0,00901^{\star * *} \\
(0,00108)\end{array}$ & $\begin{array}{c}0,0183^{* * *} \\
(0,00146)\end{array}$ \\
\hline Inseguridad1_orig & $\begin{array}{r}0,00248^{*} \\
(0,00149)\end{array}$ & $\begin{array}{l}-0,00518^{* * *} \\
(0,00145)\end{array}$ \\
\hline Inseguridad2_orig & $\begin{array}{c}0,0370^{* * *} \\
(0,00329)\end{array}$ & $\begin{array}{c}0,0163^{* * *} \\
(0,00321)\end{array}$ \\
\hline Inseguridad3_orig & $\begin{array}{l}0,0235^{\star \star \star} \\
(0,00214)\end{array}$ & $\begin{array}{l}0,00569^{\star \star \star *} \\
(0,00210)\end{array}$ \\
\hline Inseguridad1_dest & $\begin{array}{l}-0,0469^{* * *} \\
(0,0119)\end{array}$ & \\
\hline Inseguridad2_dest & $\begin{array}{l}-0,0939^{* * *} \\
(0,0124)\end{array}$ & $\begin{array}{l}-0,159^{* * *} \\
(0,0178)\end{array}$ \\
\hline Inseguridad3_dest & $\begin{array}{l}-0,0693^{* * *} \\
(0,0117)\end{array}$ & $\begin{array}{l}-0,111^{* * *} \\
(0,0194)\end{array}$ \\
\hline $\begin{array}{l}\text { NOTA: Entre paréntesis } \\
\text { estándar. }{ }^{* *} p<0,01,{ }^{* *} \\
\text { FUENTE: Elaboración }\end{array}$ & $\begin{array}{l}\text { aparecen los valores } \\
<0,05 y^{*} p<0,1 \\
\text { ropia. }\end{array}$ & de los errores \\
\hline
\end{tabular}

variable independiente de interés. El Cuadro 5 muestra las elasticidades derivadas de los modelos anteriores. Si bien se observa, en línea con la literatura (OIM, 2018), que el PIB per cápita de los países de origen y destino es el principal factor explicativo de la existencia de stocks de migrantes forzados entre África y Europa, las elasticidades obtenidas parecen apuntar a que la inseguridad alimentaria de cualquier nivel en origen afectaría a la probabilidad de que existan stocks de migrantes forzados 
en una magnitud similar a otros factores ampliamente estudiados por la literatura, como la estabilidad política. Además, se encuentra que afectarían en mayor medida a la probabilidad de que existan solicitudes de asilo que a la existencia de stocks de migrantes que finalmente son acogidos en condición de refugio. De igual modo, cabe mencionar que la inseguridad alimentaria en el país de destino se mostraría como un factor más relevante que la inseguridad alimentaria en origen.

Finalmente, merece la pena dedicar unas líneas a los resultados relacionados con las variables de control. En efecto, como sería de esperar un mayor PIB per cápita en origen reduce la probabilidad de que se observen migraciones forzadas para todas las categorías consideradas, mientras que un mayor PIB per cápita en el destino incrementa dicha probabilidad. Lo mismo ocurre con la estabilidad política y ausencia de violencia o terrorismo. Una mayor estabilidad en destino predeciría mayor probabilidad de observar migraciones forzadas, mientras que la estabilidad política en origen disminuiría dicha probabilidad. Finalmente, las muertes por desastres naturales parecen no tener un efecto significativo en el caso de las migraciones forzadas entre África y Europa.

\section{Conclusiones}

En las últimas décadas, los movimientos migratorios han experimentado un importante ascenso a nivel global (OIM, 2018). En Europa, estas presiones migratorias se han hecho notar de forma más acusada en los últimos años: solo en el período 2012-2017, el número de migrantes en la UE aumentó hasta en un 30 \% (Eurostat, 2019a, b); de estos, cerca de la mitad de los migrantes $(45,1 \%)$ proceden de países no miembros de la UE. Dada la cercanía geográfica con regiones que sufren elevadas presiones migratorias $-i$. e. África, Oriente Medio, los Balcanes o Asia del Sur-, los mecanismos de la Unión Europea se han revelado insuficientes para gestionar el repentino incremento en la entrada de migrantes (Comisión Europea, 2016).
En África la situación no es muy distinta. En esta región, los flujos migratorios se encuentran también en alza, ya sea forma de desplazamientos internos (dentro de un mismo país), migraciones intrarregionales (desplazamientos entre países del continente africano), o en los flujos hacia otros continentes -principalmente Europa (OIM, 2019). Entre los catalizadores de estos procesos, se apunta al estallido de conflictos de diversa índole o a las condiciones climáticas que afectan a la agricultura y los medios de subsistencia (FAO, 2017). La inseguridad alimentaria se considera asimismo como uno de los factores que podrían estar influenciando la tendencia creciente en los flujos de migrantes en esta región, si bien su influencia sobre los patrones migratorios hacia el continente europeo ha sido escasamente estudiada.

En este contexto, nuestro objetivo es analizar la influencia de la existencia de crisis alimentarias en los patrones de migraciones forzadas (i. e. refugiados y solicitantes de asilo) desde África hacia Europa. Para ello utilizamos una muestra de 97 países pertenecientes a los dos continentes para el período 2000-2018, utilizando como metodología un exhaustivo análisis descriptivo y modelos de tipo probit.

Un análisis exploratorio de los datos parece indicar que la mayor parte de los movimientos migratorios forzados con origen en África lo son en forma de desplazamientos internos (dentro del mismo país) o hacia otros países africanos. Solo una pequeña proporción de los mismos constituyen flujos hacia Europa. Esto es consistente con algunos estudios que apuntan a que a menudo los desplazamientos se producirían en primer lugar de las zonas rurales a las urbanas, solo abordando la movilidad internacional si la situación que lo motivó persiste (FAO, IFAD, IOM y WFP, 2018).

Con respecto a la composición de dichos flujos, nuestro análisis muestra que la mayor parte de los flujos de migrantes forzados procedentes de África en dirección a Europa parten de África subsahariana (94\% en media a lo largo del período). Dentro del continente europeo, es la UE la que acoge la mayor proporción de los migrantes con origen africano (un 
$72 \%$ de media). Entre los desplazamientos internos y migraciones intrarregionales en el continente africano, la situación es similar. La amplia mayoría de los migrantes partirían de África subsahariana, si bien se observa que la mayoría de estos desplazamientos son internos o se producen hacia otros países de África subsahariana. Únicamente una pequeña proporción se desplazaría hacia el norte de África.

En cuanto al análisis econométrico, los resultados del mismo parecen indicar que, si bien el PIB per cápita de los países de origen y destino se muestra como el principal factor a la hora de explicar la probabilidad de que un determinado país europeo mantenga un cierto stock de migrantes forzados con origen africano, la inseguridad alimentaría incidiría también en esta probabilidad incluso una vez tenidos en cuenta otros factores como la existencia de inestabilidad política y violencia, los desastres naturales o las propias diferencias de PIB per cápita entre los países de origen y destino ya comentadas. Asimismo, se observa que el efecto es mayor para el caso de la inseguridad alimentaria en destino que la del país de origen. Además, este efecto sería sustancialmente inferior para el caso de las acogidas en condición de refugio (stock de refugiados) que para la probabilidad de que existan peticiones de asilo, lo que sería consistente con las conclusiones de algunos estudios que señalan que de las solicitudes de asilo recibidas en el denominado "occidente», solo una parte es aceptada dando lugar al estatus de refugiado (Hatton, 2009).

Los resultados de este estudio arrojan, por tanto, importantes conclusiones de política pública, en la medida en la que confirmarían empíricamente los hallazgos encontrados en otros estudios acerca de que la migración podría estar constituyendo una estrategia para escapar de los efectos de la seguridad alimentaria entre la población africana (FAO, 2016; Concern Worldwide/ Welthungerhilfe, 2000). Así, los inmigrantes partirían en mayor medida de países en los que la inseguridad alimentaria es superior, buscando refugio en otros con mayores niveles de seguridad alimentaria, siendo de hecho la influencia de la inseguridad alimentaria en destino mayor que la de origen.

Finalmente, nos gustaría reconocer algunas limitaciones de este estudio que creemos pueden constituir interesantes líneas de investigación para futuros trabajos. En este sentido, en nuestro artículo nos hemos centrado en estudiar el denominado margen extensivo, es decir, la probabilidad de que existan los stocks de migrantes forzados. Sería, sin embargo, interesante conocer también qué factores pueden afectar al margen intensivo o intensidad de dichos flujos para los cuales otros métodos, como el modelo de gravedad utilizando una distribución del tipo poisson de pseudo-máxima verosimilitud (PPML, por sus siglas en inglés) podría revelarse más adecuado.

\section{Referencias bibliográficas}

ACNUR (2015). Tendencias Globales. Desplazamiento forzado en 2015. https://www.acnur.org/fileadmin/Documentos/Publicaciones/2016/10627.pdf

ACNUR (2017). Global Report on Internal Displacement - Global Trends - Forced displacement in 2017. Geneva.

Bodvarsson, Ö. B., \& Van den Berg, H. (2013). The Economics of Immigration: Theory and Policy. Second edition. Dordrecht, New York: Springer.

Borjas, G. J. (1989). Economic Theory and International Migration. International Migration Review, 23(3), 457-485.

Castles, S., y Miller, M. (2004). La era de la migración. Movimientos internacionales de población en el mundo moderno. Universidad Autónoma de Zacatecas, México: Miguel Ángel Porrúa.

Comisión Española de Ayuda al Refugiado (2016). Movimientos migratorios en España y Europa. https://www.cear.es/ wp-content/uploads/2017/02/Informe-rutas-migratorias.pdf

Comisión Europea (2016). La UE y la crisis migratoria. https:// op.europa.eu/en/publication-detail/-/publication/e9465e4fb2e4-11e7-837e-01aa75ed71a1/language-es

Comisión Europea (2018). Standard Eurobarometer 90 - Autumn 2018 "Public opinion in the European Union, First results". Survey conducted by Kantar Public at request of the European Comission.

Concern Worldwide/ Welthungerhilfe (2000). Global Hunger Index. Forced migration and Hunger. Dublin/Bonn.

Eurostat (2019a). Estadísticas de migración y población migrante. https://ec.europa.eu/eurostat/statistics-explained/ index.php?Title=Migration_and_migrant_population_statistics/es\#Poblaci.C3.b3n_migrante:_en_la_UE_viv. 
C3.adan_22.2C3.C2.a0millones_de_ciudadanos_de terceros_pa.C3.adses_a_fecha_de_1_de_enero_de_2018

Eurostat (2019b). Estadísticas de migración y población migrante. https://ec.europa.eu/eurostat/statistics-explained/index. php?Title=Migration_and_migrant_population_statistics/es

FAO (2011). Una introducción a los conceptos básicos de la seguridad alimentaria. http://www.fao.org/3/al936s/al936s00.pdf

FAO (2016). Migration, agriculture and rural development. http:// www.fao.org/3/a-i6064e.pdf

FAO (2017). Regional Overview of Food Security and Nutrition in Africa 2017. The food security and nutrition-conflict nexus: building resilience for food security, nutrition and peace. Accra. http://www.fao.org/3/a-i7967e.pdf

FAO, FIDA y PMA (2015). El estado de la inseguridad alimentaria en el mundo 2015. Cumplimiento de los objetivos internacionales para 2015 en relación con el hambre: balance de los desiguales progresos. Roma, Italia.

FAO, IFAD, IOM y WFP (2018). The Linkages between Migration, Agriculture, Food Security and Rural Development. Technical report. http://www.fao.org/3/CA0922EN/CA0922EN.pdf

Gamboa, M. G. (2018). Salida y llegada a Ecuador. Procesos de inserción de los refugiados sirios a la sociedad ecuatoriana. Repositorio Digital FLACSO, Ecuador. https://repositorio.flacsoandes.edu.ec/bitstream/10469/14649/2/TFLACSO-2018MGGM.pdf

Greene, W. (2018). Econometric Analysis, 8th ed.; Prentice Hall: Upper Saddle River, NJ, USA.

Hatton, T. J. (2004). Seeking asylum in Europe. Economic Policy, 19(38), 5-62. https://econpapers.repec.org/repec:bla:ecpoli: v:19:y:2004:i:38:p:5-62

Hatton, T. J. (2009). The Rise and Fall of Asylum: What Happened and Why? The Economic Journal, 119(535), 183-213.

Joint Research Center (2018). International Migration Drivers. EUR 29333 EN. http://publications.jrc.ec.europa.eu/repository/handle/JRC112622

Lee, E. S. (1966). A Theory of Migration. Demography, 3(1), 4-57.

León, A. M. (2005). Teorías y conceptos asociados al estudio de las migraciones internacionales. Trabajo Social, (7), 59-76.

Lucas, R. E. (2006). Migration and economic development in Africa: A review of evidence. Journal of African Economies, 15(2), 337-395.

Ministerio de Asuntos Exteriores (2018). Las migraciones en África. http://www.exteriores.gob.es/Portal/es/politicaexteriorcooperacion/Africa/Documents/20180724_ARTICULO.pdf
OCDE-FAO (2016). Perspectivas Agricolas 2016-2025. https:// www.oecd-ilibrary.org/agriculture-and-food/ocde-fao-perspectivas-agricolas-2016-2025/agricultura-en-africa-subsahariana_agr_outlook-2016-5-es

OIM (2011). International Migration Law n²5. Glosary on Migration. Geneva, IOM.

OIM (2018). Informe sobre las Migraciones en el Mundo 2018. Suiza.

OIM (2019). Informe sobre las Migraciones en el Mundo 2020. Ginebra.

Pascual, A. (2014). Las causas estructurales de la inseguridad alimentaria en África del Este: un acercamiento a los factores socioeconómicos, políticos y culturales que obstaculizan el acceso al alimento en la región. Instituto Universitario de Desarrollo y Cooperación IUDC-UCM.

Pérez, K. (2011). Crisis alimentaria y lucha contra el hambre en el África subsahariana. La cuestionable contribución de los ODM. Revista de Economía Mundial, (27), 117-148.

PMA (2017). Los orígenes del éxodo: inseguridad alimentaria, conflictos y migración internacional . Roma.

PMA, OIM y LSE (2015). Hambre sin Fronteras. Los Vínculos Ocultos entre Inseguridad Alimentaria, Violencia y Migración en el Triángulo Norte de Centroamérica. Un estudio exploratorio. Documento no ha sido sometido a una revisión editorial.

PMA, OIM, BID, FIDA y OEA (2017). Seguridad alimentaria y emigración: por qué la gente huye y el impacto que esto tiene en las familias que permanecen en El Salvador, Guatemala y Honduras. Reporte de investigación.

Rademacher-Schulz, C., Schraven, B., \& Salifu, E. (2014). Time matters: shifting seasonal migration in Northern Ghana in response to rainfall variability and food insecurity. Climate and Development, 6(1), 46-52.

Ravenstein, E. G. (1885). The Laws of Migration. Journal of the Statistical Society of London, 48(2), 167-235.

Regassa, N., \& Stoecker, B. (2011). Household food insecurity and hunger among households in Sidama district, southern Ethiopia. Public health nutrition, 15(7),1276-1283. · December 2011. Sassen, S. (2007). Una Sociologia de la Globalizacion.

Tegegne, A. D., \& Penker, M. (2016). Determinants of rural out-migration in Ethiopia: Who stays and who goes? Demographic research, 35, 1011-1044.

Wooldridge, J. M. (2010). Econometric Analysis of Cross-section and Panel Data, 281-344. Second ed. Cambridge, Massachusetts: MIT Press. 